\title{
Nordiques
}

33 | 2017

La transition des villes nordiques : quelles innovations territoriales en périphérie?

\section{Aladin Larguèche, Christiania (1811-1869)}

Presses universitaires du Midi, 2015

\section{Frédérique Harry}

\section{(QpenEdition \\ Journals}

Édition électronique

URL : https://journals.openedition.org/nordiques/3403

DOI : $10.4000 /$ nordiques.3403

ISSN : 2777-8479

Éditeur :

Association Norden, Bibliothèque de Caen la mer

Édition imprimée

Date de publication : 1 mai 2017

Pagination : 140-141

ISBN : 978-2-9544654-9-4

ISSN : 1761-7677

\section{Référence électronique}

Frédérique Harry, « Aladin Larguèche, Christiania (1811-1869) », Nordiques [En ligne], 33 | 2017, mis en ligne le 19 janvier 2022, consulté le 02 février 2022. URL : http://journals.openedition.org/nordiques/ 3403 ; DOI : https://doi.org/10.4000/nordiques.3403

Ce document a été généré automatiquement le 2 février 2022.

Nordiques 


\section{Aladin Larguèche, Christiania (1811-1869)}

Presses universitaires du Midi, 2015

\section{Frédérique Harry}

\section{RÉFÉRENCE}

Aladin Larguèche, Christiania (1811-1869, Presses universitaires du Midi, 2015, 436 pages

1 S'appuyant sur une approche historique solidement documentée, Aladin Larguèche étudie la formation d'une identité et d'un espace littéraires norvégiens dans un contexte de construction nationale et de mutation religieuse. L'auteur interroge la notion de «transfert de sacralité » dans l'espace littéraire, à la fois représentatif et acteur de mutations sociales et religieuses, au prisme de l'esthétique et la naissance des belles-lettres comme objet en soi, de leur place et de leur traitement.

2 L'ouvrage comporte 436 pages et se partage en trois grands moments: la contextualisation, une étude sociohistorique des auteurs et une analyse thématique des données récoltées. Si les premiers chapitres reviennent en détail sur le contexte de la capitale et le rôle de l'université de Christiania, la seule du pays, c'est l'étude exhaustive des «écrivants " norvégiens de 1814 à 1868 qui constitue l'un des tours de force de cet ouvrage : l'auteur y étudie, grâce à une analyse sociologique et à l'outil statistique, l'identité des acteurs de la vie littéraire selon une classification périodique.

3 La connaissance très approfondie de la production écrite norvégienne entre 1811 et 1869 permet de relativiser la thèse communément admise selon laquelle l'émergence d'une pensée nationaliste se formerait en parallèle de la déchristianisation d'une société. Certes, le " retrait des théologiens de la vie esthétique ", constatée à partir de la seconde moitié du siècle, «serait l'un des avatars d'un phénomène plus large de spécialisation du travail intellectuel »(p.334). Mais ce serait oublier la persistance d'une littérature religieuse dans les campagnes où les réveils sont bien implantés et le 
renforcement inattendu de la position des pasteurs dans la production écrite des années 1860. Ce constat nuance le postulat selon lequel il y a "corrélation entre productivité littéraire et sécularisation des pratiques d'écriture» (p. 231). On peut cependant s'interroger à la suite de l'hypothèse formulée par l'auteur : la contre-percée théologienne - concomitante à la percée moderne - confirme la spécialisation qui touche la littérature. Mais ces théologiens qui « sortent du sérail académique » (p. 241) ne le réinvestiraient-ils pas d'une façon moderne en le consacrant à leur vocation religieuse?

4 L'auteur n'explore pas uniquement le domaine spirituel et ouvre son analyse à l'ensemble des productions écrites, avec en ligne d'horizon - et comme date butoir de l'étude - les débuts de la percée moderne. S'il est communément admis que ce mouvement est porté par l'émergence des nouvelles professions intellectuelles contestant la dominance traditionnelle de l'élite académique, l'auteur invite à nuancer cette hypothèse, en rappelant que les bourgeois académiques conservent une position dominante dans le champ littéraire à une époque où vivre de la plume reste encore difficile. Et se rapprochant de la thèse de Narve Fulsås, Aladin Larguèche discute les ramifications du mouvement : si la presse est un espace d'engagement prisé des auteurs de la percée moderne, c'est aussi parce que le journalisme permet une rente d'argent qui mène les "poétocrates" à "embrasser le combat idéologique pour pouvoir compenser la faiblesse économique du statut des belles-lettres dans la société. Ce faisant, ils redéfinissent aussi les normes, formes et contenus de la production littéraire : le goût littéraire se réinvente indépendamment des critères universitaires " (p. 247). Il s'opère une distanciation entre la pratique littéraire, le jugement public de la chose esthétique et la construction d'une expertise.

5 Le religieux est-il pour autant exclu du domaine littéraire ? Loin de là. L'intérêt pour "l'esthétique profane» (p.405) reste vif chez les théologiens, même vers la fin du siècle, comme l'illustre l'exemple de Marcus Jacob Monrad. Dans son Esthétique parue en 1889, ce dernier développe les concepts nécessaires à une " autonomie normative du champ esthétique» sans occulter la dimension religieuse qui $\mathrm{y}$ demeure « incontournable» (p.347). L'approche monradienne est ainsi présentée comme un « code moral d'origine luthérienne où la religion est à la fois une prise de conscience subjective, une instance éthique suprême, mais aussi une institution sociale objective, devant permettre aux hommes de vivre en société » (ibid.).

6 Les atouts de l'ouvrage résident incontestablement dans la rigueur et l'érudition dont l'auteur fait preuve. L'utilisation de méthodes de recherche modernes et systématiques permet le traitement et l'analyse d'un large corpus. Aladin Larguèche propose ainsi une somme remarquable sur l'histoire de la littérature et des idées, une analyse originale et nuancée d'une des dimensions de la sécularisation en Norvège, tout en ouvrant régulièrement des pistes d'analyse (nous pensons ici aux mentions systématiques faites aux auteures) qui suscitent la curiosité et, espérons-le, des études complémentaires. 